\title{
CONTRIBUIÇÕES DA PSICOLOGIA PARA A FORMAÇÃO DO TÉCNICO EM ENFERMAGEM: CONCEPÇÕES DOS ALUNOS
}

\author{
Fernanda Azevedo Esquerdo* \\ Renata Fabiana Pegoraro"
}

\begin{abstract}
RESUMO. O presente trabalho é uma pesquisa de campo qualitativa e descritiva com o objetivo de investigar as concepções de estudantes de um curso técnico em enfermagem no Estado do Rio de Janeiro sobre suas expectativas em relação à disciplina "Psicologia Aplicada à Enfermagem" e os subsídios por ela oferecidos para sua atuação profissional. Foram entrevistados dez alunos de um curso técnico em enfermagem ministrado em um município do Estado do Rio de Janeiro a partir de roteiro semiestruturado. A análise do conteúdo das entrevistas indicou o impacto emocional que o aluno experimenta no início do estágio profissionalizante e a necessidade de receber, ao longo da disciplina, "receitas prontas" para lidar com as dificuldades emocionais encontradas no hospital.
\end{abstract}

Palavras-chave: Psicologia; educação em enfermagem; ensino médio.

\section{CONTRIBUTIONS OF THE PSYCHOLOGY TO THE TECHNICAL TRAINING IN NURSING: CONCEPTIONS OF STUDENTS}

\begin{abstract}
The current work is a qualitative and descriptive field research in order to investigate the conceptions of students from a technical course in nursing in the State of Rio de Janeiro on their expectations in relation to the subject "Psychology Applied to Nursing" and the subsidies offered by it for their professional activities. We interviewed ten students from a technical course in nursing in a city of Rio de Janeiro State, using a semi structured guide. The analysis of the content of the interviews indicated the emotional impact that the student experiences in the early period of training and the need to get from the discipline the easiest and the best way of dealing with the emotional difficulties encountered in hospital.
\end{abstract}

Key words: Psychology; nursing education; high school.

\section{CONTRIBUCIONES A LA PSICOLOGÍA DE LA FORMACIÓN TÉCNICA EN ENFERMERÍA: CONCEPCIONES DE LOS ESTUDIANTES}

\begin{abstract}
RESUMEN. Esta es una investigación de campo cualitativo y descriptivo con respecto a investigar las concepciones de los estudiantes de los cursos de técnico en enfermería en el Estado de Río de Janeiro sobre sus expectativas frente a la "Psicología Aplicada a la Enfermería" y las subvenciones ofrecidas por la misma para su desempeño profesional. Entrevistamos a 10 alumnos en un curso de enfermería en cursos Consejo Técnico del Estado de Río de Janeiro a partir de entrevistas semi-estructuradas guía. El análisis del contenido de las entrevistas se indica el impacto emocional que el estudiante experiencias en la primera etapa de la formación y la necesidad de obtener más de la disciplina, "los ingresos listo "para hacer frente a las dificultades encontradas emocional en el hospital.
\end{abstract}

Palabras-clave: Psicología; educación en enfermería; escuela secundaria.

As concepções expressas na Constituição Federal do Brasil e em outros dispositivos legais apontam para um conceito ampliado de saúde, que envolve a necessidade de resgatar a subjetividade no cuidar e o reconhecimento da integralidade como um princípio que contempla as dimensões biológicas, psicológicas e sociais do ser humano, provocando mudanças nas orientações pedagógicas das instituições responsáveis pela formação de recursos humanos para a área da saúde no país. Esse novo olhar que se constrói no campo da saúde vem sendo progressivamente difundido como uma "nova cultura da saúde" não apenas na educação superior, mas também na educação profissional de nível médio.

\footnotetext{
Psicóloga. Especialista em Psicologia Hospitalar. Psicóloga da Prefeitura Municipal de Casimiro de Abreu, RJ, Brasil.

\# Psicóloga. Doutora em Psicologia. Professora Titular da UNIP - Campus Flamboyant (Goiânia).
} 
Considerando-se que $65 \%$ da força de trabalho em saúde no país são constituídos de trabalhadores da área de Enfermagem, torna-se evidente a importância desta área para o panorama geral da assistência (Diretrizes Curriculares Nacionais para o Ensino Técnico, Área da Saúde, 1999). No Estado do Rio de Janeiro, no mês de julho de 2008 encontravam-se inscritos no Conselho Regional de Enfermagem (Conselho Regional de Enfermagem do Rio de Janeiro, 2008) um total de 24.621 enfermeiros (nível superior), 82750 técnicos (nível médio) e 71510 auxiliares de enfermagem (ensino fundamental).

Apesar do grande número de técnicos registrados no referido conselho, este parcela dos profissionais de Enfermagem é pouco explorada pela literatura. Para contemplar a necessidade de uma formação que envolva habilidades cognitivas, técnicas e de relações humanas, a formação profissional de nível médio na área de enfermagem envolve, além de disciplinas mais estritamente ligadas à área biológica - como Higiene ou Microbiologia -, ramos do conhecimento como Sociologia, Filosofia e Psicologia, responsáveis pelas bases ética, política e social do trabalho em saúde.

Diante destas considerações, o objetivo proposto para este artigo é investigar as concepções de alunos de curso técnico em enfermagem no tocante à disciplina "Psicologia aplicada à Enfermagem", para identificar suas expectativas com relação à disciplina e verificar se ela fornece subsídios para perceber aspectos psicológicos envolvidos no processo de adoecer e na interação interpessoal.

\section{O ensino da Enfermagem no Brasil e as contribuições da Psicologia ao ensino técnico nesta área}

A organização da Enfermagem enquanto profissão teve início no século XIX, com o treinamento para o exercício da atividade na área psiquiátrica. Já a primeira tentativa de profissionalização em nosso país surgiu em 1890, com a criação da Escola Profissional para Enfermeiros e Enfermeiras, ligada à Universidade Federal do Estado do Rio de Janeiro (UNIRIO), tendo como objetivo explícito prepará-los para a atividade nos hospícios e hospitais civis e militares, por meio de cursos com dois anos de duração (Fontenele Júnior, 2002).

A partir de 1930 foi promulgada uma série de decretos, pareceres e leis no intuito de regulamentar o ensino e o exercício da Enfermagem no Brasil. O Decreto 20.109/31 marcou a consolidação do exercício profissional de enfermagem e equiparação das escolas à Ana Neri (escola padrão). Na década de 1940 surgiram novas escolas de ensino técnico e superior em Enfermagem. A Lei 2604/55, regulamentada pelo Decreto 50.387/61, disciplinou o exercício da Enfermagem no Brasil, e a Lei 4.024/61 estabeleceu novas diretrizes e bases da educação nacional, prevendo a formação de enfermagem em nível técnico para preencher lacuna deixada entre o exercício de cuidados elementares (efetuados pelos auxiliares) e funções de chefia/magistério (graduado). O Parecer 3.814/76 do Conselho Federal de Educação (CFE) promoveu a revisão dos conteúdos mínimos estabelecidos pelo Parecer 45/72 que delimitavam o ensino técnico (Dantas \& Aguillar, 1999; Avello \& Grau, 2004; Ribeiro, 2002).

A Lei 7.498/86 (regulamentada pelo Decreto-Lei 94.406/87) dispõe sobre o exercício da enfermagem, estipulando que passaria a ser exercida privativamente pelo enfermeiro, técnico, auxiliar de enfermagem e parteira, de acordo com os respectivos graus de habilitação (Dantas \& Aguillar, 1999; Avello \& Grau, 2004; Ribeiro, 2002).

A partir de 1999, por força da Resolução 04/99 do Conselho Nacional de Educação, as "Diretrizes Curriculares Nacionais - Área da Saúde" (DCNAS) passaram a orientar e nortear todos os cursos técnicos de saúde, inclusive os de enfermagem. Tendo como orientação as determinações da LDB - Leis de Diretrizes e Bases da Educação - e do Decreto 2.208/97, bem como as recomendações aprovadas pelo Conselho Nacional de Educação/MEC, tais diretrizes representaram um processo de ruptura e de transição para um ensino médio significativamente diferente do atual, ao abranger o caráter profissionalizante e a natureza humanística no enunciado das suas competências, habilidades e bases científicas indispensáveis para a formação técnica em saúde (Diretrizes Curriculares Nacionais para o Ensino Técnico Área da Saúde, 1999). A Resolução 04/99 apresenta critérios para a organização e o planejamento dos cursos que atendem a demandas da sociedade e do mercado aliadas à vocação do profissional e às capacidades da escola que oferece o cursos técnico. Além de uma carga horária delimitada, exige-se que o curso permita o desenvolvimento de competências profissionais - gerais no caso de todos os cursos do campo da saúde e específicas da enfermagem, aqui em foco (Bagnato, Bassinello, Lacaz \& Missio, 2007).

Seguindo-se as concepções expressas na Constituição da República Federativa do Brasil e nos dispositivos legais infraconstituicionais (leis 8080/90 e 8142/90), passou-se a formular um conceito ampliado de saúde, não redutível à sua dimensão setorial de sistemas de serviços, e um conjunto de princípios balizadores centrados na integralidade, universalidade 
e equidade da atenção. Dessa forma, as instituições formadoras e de assistência em saúde colocaram-se diante de dois desafios: de um lado, ensinar e produzir cuidados de saúde integrais, e do outro, interagir, dialogar e pactuar com outros setores econômicos e sociais que determinam ou condicionam o estado de saúde da população (Bagnato, Bassinello, Lacaz \& Missio, 2007).

De acordo com as DCNAS, a nova visão de qualidade em saúde inclui a humanização do cuidado na perspectiva do cliente, contrária à produção do cuidado caracterizada como exaustiva e fragmentada por intervenções múltiplas de distintos profissionais. A discussão a respeito desse processo de trabalho no tempo introduziu a questão da equipe de saúde, onde se insere o profissional de nível médio na interação com o cliente, exercendo atividades de planejamento, execução e gerenciamento do cuidado. Para realizar a interação com o cliente, de acordo com as Diretrizes Curriculares Nacionais para o Ensino Técnico (1999), o profissional de nível médio deve ser qualificado em múltiplos aspectos, tais como: habilidades cognitivas, de abstração e análise simbólica, comunicacionais, e de inter-relação com clientes e demais trabalhadores; iniciativa e criatividade; capacidade de trabalhar cooperativamente em grupo e para a formação mútua no próprio local de trabalho; competência para avaliar o produto do seu trabalho e tomar medidas para melhorar a sua qualidade; e domínio de técnicas de planejamento e organização do trabalho (p.7).

No caso da saúde, o processo de trabalho requer: a integração das intervenções e atividades profissionais, destacando o caráter multiprofissional de prática; o redimensionamento da liberdade de decisão e conduta de cada agente; a articulação dos conhecimentos oriundos de várias disciplinas ou ciências, destacando o caráter interdisciplinar da prática; e maior qualificação profissional, tanto na dimensão técnica especializada quanto na dimensão ético-política, comunicacional e de inter-relações pessoais.

Ao propor o diálogo com as Ciências Humanas, a Enfermagem obtém, a partir da disciplina de Psicologia, a leitura de fenômenos emocionais que intervêm na situação de doença, criando e ampliando a compreensão da situação singular de cada pessoa. Além disso, também aperfeiçoa o atendimento aos pacientes e o relacionamento da equipe, na medida em que, ao enfocar a interação humana de maneira científica e humanizada, possibilita o esclarecimento de variáveis relevantes e possíveis dificuldades presentes em tais relacionamentos, bem como a troca de conhecimentos entre todos os agentes envolvidos no processo saúde-doença.

\section{TIPO DE ESTUDO, PARTICIPANTES E LOCAL}

O estudo, desenvolvido a partir de abordagem qualitativo-descritiva, teve como participantes dez alunos de um curso técnico em Enfermagem oferecido por uma escola da região dos Lagos, no Estado do Rio de Janeiro. Como critério de seleção para participar do estudo foi estabelecido que o aluno deveria ter concluído a disciplina "Psicologia Aplicada à Enfermagem" e iniciado estágio prático profissionalizante.

A duração do curso técnico era de 18 meses, num total de 1800 horas (600 reservadas ao estágio supervisionado) e englobava tanto disciplinas como Fisiologia, Anatomia, Microbiologia e Fundamentos de Enfermagem, Higiene e Profilaxia (que fornecem as bases científicas para a compreensão do processo saúde-doença, de acordo com seu campo de atuação e técnicas específicas da profissão), como disciplinas da área de Humanas, como "Ética" e "Psicologia Aplicada à Enfermagem". Estas tinham o objetivo de possibilitar ao aluno os recursos cognitivos e socioafetivos que deverão permear o seu trabalho como técnico de enfermagem.

A disciplina "Psicologia Aplicada à Enfermagem", ministrada por um Psicólogo com diploma de licenciatura na área ao longo de 30 horasaula, apresentava na ementa os seguintes tópicos: a) Noções gerais de Psicologia; b) Considerações sobre relações humanas; c) Personalidade; d) Temperamento e caráter; e) Aparelho psíquico do ser humano e planos de manifestações mentais; f) Mecanismos de defesa do ego; g) Sensação e percepção e períodos do desenvolvimentos humano.

\section{Instrumento utilizado}

Os participantes concederam entrevista a partir de roteiro semiestruturado elaborado com base em dois eixos temáticos: a) concepções dos alunos sobre a forma como foi ministrada a disciplina "Psicologia Aplicada à Enfermagem" (didática de ensino da disciplina, adequação da carga horária) e suas expectativas em relação à disciplina; b) contribuições dos conteúdos estudados na disciplina quanto à compreensão de aspectos emocionais do paciente e relação entre os conteúdos abordados e a prática profissional vivenciada durante o estágio profissionalizante e no relacionamento interpessoal. 


\section{Aspectos éticos}

O projeto de pesquisa foi apreciado e aprovado pelo Comitê de Ética da Universidade Veiga de Almeida, por meio da Resolução 84/2007. Todos os participantes receberam uma carta explicativa sobre a pesquisa, com o intuito de detalhar o estudo e obter consentimento para a realização da entrevista. Após a leitura desta carta, foi entregue a cada participante o "Termo de Consentimento Livre e Esclarecido" (TCLE), em duas vias, que garante o sigilo quanto à identidade do entrevistado, bem como assegura sua livre participação e, se o desejar, a interrupção dessa participação a qualquer momento.

\section{Realização das entrevistas e forma de análise de dados}

As entrevistas foram gravadas em áudio, mediante a permissão dos participantes, e após transcrição literal, foram analisadas de acordo com a proposta de Biasoli-Alves e Dias-da-Silva (1992). As autoras sugerem que, transcritas, as entrevistas sejam lidas de forma cuidadosa, inicialmente uma a uma e, em seguida, em seu conjunto, de forma a permitir a identificação de temas centrais. A partir disso, por meio de movimento constante entre os temas identificados e a literatura disponível (no caso do presente estudo, a legislação vigente e a produção científica atual sobre o assunto), são identificadas as categorias de análise.

Com vista à preservação da identidade dos participantes, adotou-se a designação "E1" para aquele que cedeu a primeira entrevista, e assim sucessivamente até a última entrevista, na qual o aluno recebeu a sigla "E10".

\section{RESULTADOS}

\section{Caracterização dos entrevistados}

Dentre os participantes do estudo, oito eram mulheres. Suas idades variavam entre 24 e 54 anos. Sete deles eram solteiros e os demais, casados. Com relação às ocupações, três entrevistados declararam atuar na área de saúde, dois dedicavam-se ao lar, dois trabalhavam na área de secretariado, um na área de vendas, um como professor e apenas era estudante (quadro 1).

\begin{tabular}{|l|l|l|l|l|}
\hline Entrevista & Sexo & Idade (anos) & Estado Civil & Ocupação Atual \\
\hline E 1 & M & 27 & Casado & Professor \\
\hline E 2 & M & 33 & Solteiro & Agente comunitário de saúde \\
\hline E 3 & F & 28 & Solteira & Promotora de vendas \\
\hline E 4 & F & 41 & Solteira & Recepcionista de unidade básica de Saúde \\
\hline E 5 & F & 32 & Solteira & Dona de Casa \\
\hline E 6 & F & 36 & Solteira & Secretária \\
\hline E 7 & F & 36 & Casada & Dona de Casa \\
\hline E 8 & F & 24 & Solteira & Estudante \\
\hline E 9 & F & 54 & Casada & Recepcionista de unidade básica de Saúde \\
\hline E 10 & F & 40 & Solteira & Auxiliar de Secretaria \\
\hline
\end{tabular}

Quadro 1 - Caracterização dos Alunos que Participaram do Estudo

\section{Análise das entrevistas}

Psicologia aplicada à Enfermagem: ferramenta para conhecer o comportamento humano e compreender o paciente integralmente

Ao analisarmos as concepções dos estudantes entrevistados, percebemos que a disciplina "Psicologia Aplicada à Enfermagem" foi por eles apresentada como ferramenta importante para conhecer o comportamento humano e compreender o paciente que recebe seu cuidado. A partir dos conteúdos discutidos na disciplina, alguns entrevistados passaram a perceber, com mais atenção, as reações emocionais dos pacientes, como a alegria e a tristeza. Outra mudança foi a possibilidade de refletir sobre e perceber a influência dos aspectos físicos da doença sobre o psiquismo do paciente, bem com a influência dos aspectos psicológicos refletidos no sofrimento físico, como ilustrou um dos entrevistados:

Não é só a enfermidade que ele tem ali, mas olhando como um todo, né? O ser humano como um todo, o lado psicológico também, né? As mudanças de comportamento, as reações, alegria, tristeza, tudo isso, sabe? Me ajudou muito. (E7)

Outro entrevistado complementa: 
Eu já peguei paciente que não tinha melhoras no quadro, não porque estavam sendo tratados devidamente ... não tinha os filhos por perto... então tudo isso influencia na evolução clínica do paciente, né? O psicológico é muito forte na gente, então se o nosso psicológico não está legal, o físico, ele vai pagar por isso, ele vai padecer por isso ...é, é, a pessoa já está doente ... a melhora não vem por causa disso. (E1)

Esse reconhecimento da "pessoa adoecida", e não apenas da doença, pode ser identificado por meio dos depoimentos sobre o "cuidar", atividade essencial da enfermagem, que os alunos definem como um ato humanitário através do qual o profissional deve atender todas as necessidades do paciente, tanto físicas quanto psicológicas. "O cuidar não é só o cuidar físico de você estar limpando, de você estar fazendo medicação. É o cuidar do geral, né?" (E1) Nas palavras de outro entrevistado: "Um apoio, né? Porque, ah ... por trás do paciente tem, tem um ser humano, né?" (E2)

De acordo com os entrevistados, a disciplina "Psicologia Aplicada à Enfermagem" também ajudou o aluno de curso técnico a lidar com o paciente a partir das singularidades por este apresentadas, já que não existe uma forma única de lidar com todos os pacientes. $\mathrm{O}$ reconhecimento desta singularidade permitiria que, ao longo do estágio, o aluno, no exercício das atividades de enfermeiro, se tornasse mais atento ao paciente, e não apenas à doença por ele apresentada. A disciplina faz com que o aluno "desperte" para a existência de aspectos subjetivos:

\section{Ela é importante porque ajuda aos profissionais a lidarem com os pacientes, porque cada paciente (...) é diferente do outro, e o técnico tem que ter um jogo de cintura pra lidar com cada paciente... Você saber lidar com o ser humano, te ajuda. Não que você vai ser "expert", você não vai ser psicólogo, mas você entender um pouquinho é válido. (E4)}

Os alunos destacaram a importância de conversar e ouvir o paciente para que ele se sinta bem e ocorra melhora em seu quadro clínico, e ainda apontam a "conversa" como o instrumento para que o profissional aborde os aspectos psicológicos do paciente, como o desequilíbrio emocional e receios decorrentes da realização de algum procedimento. Para os alunos, é na conversa com o paciente - ou melhor, na escuta, como define a Política Nacional de Humanização, que a disciplina de Psicologia se faz presente, sendo necessário que os profissionais tenham disponibilidade para conversar e ouvir o paciente, ou seja, para esclarecer e orientar, tendendo a um atendimento humanizado.

Sempre acontece alguma coisa que não só a pessoa desequilibrada que chega lá, ó, sempre eles falam "ó, tem que conversar... isso aí é parte psicológica” ... Para poder se equilibrar. De repente uma conversa ,... uma parte psicológica, eu acho que pode trazer muita importância, muita coisa para um paciente. (E6)

A disciplina de Psicologia proporcionou ainda uma ampliação da percepção dos entrevistados sobre si, e não apenas a respeito do paciente. Alguns temas discutidos em sala, como a teoria psicanalítica sobre o funcionamento do aparelho psíquico e a estratégia de "dinâmica de grupos", permitiram que alguns alunos se sentissem mais capacitados para o relacionamento interpessoal, a partir da discussão de questões de caráter pessoal/emocional dos entrevistados: "Você ser mais capacitado, enfim, para trabalhar com o público, né?...é, é, estar mais preparado para o ser humano". (E2)

\footnotetext{
Quando a gente está estudando, eles fazem jogos de dinâmica com a gente na Psicologia, entendeu?... Ah, o objetivo acho que era pra te conhecer um pouco melhor, entendeu? E eи a eu mesmo. Conhecer os meus colegas de classe. (E10)

É assim: antes de, de, de, entender a outra pessoa, a gente acaba passando, a se, a, a, a se entender, a gente passa a se analisar. $E$ quando a gente estuda os mecanismos de defesa, questão do ego, superego. (E1)
}

O impacto emocional sofrido pelo aluno ao tomar contato com a prática de Enfermagem no momento de estágio foi ressaltado pelos entrevistados. Para os alunos, o profissional de Enfermagem precisaria desenvolver algumas características psicológicas pessoais para relacionar-se com o paciente, como controle emocional, compreensão e paciência. $\mathrm{O}$ entrevistado 7 relembra o impacto emocional do início do estágio: "Eu chegava em casa, tinha horas que eu parava, ficava pensando, né? nas, nas coisas que a gente via lá dentro [do hospital] e assim às vezes eu chorava, me... me... me emocionava”. (E7) Já o entrevistado 4 ressalta características pessoas que podem atrapalhar seu desempenho: Ter a paciência, né? de tá ali...procurar não estressar, porque eu sou realmente...eu sou bem estressadinha (...) trabalhar 
calma, tranquila, dar conta do recado, tudo certinho....É bola pra frente...tocando, cada dia um plantão. (E4)

Para um dos entrevistados, a disciplina de Psicologia foi abordada de forma prática, associada ao cotidiano, podendo-se perceber sua aplicabilidade na rotina de trabalho:

\begin{abstract}
É igual à visão que a gente tem da matemática. Muitas vezes, na escola, né, se a matemática ela for passada pra você de forma prazerosa e associando a seu o cotidiano você leva mais fácil, você consegue levar a matéria mais fácil. Agora se for passada de forma chata, né? ... Não foi isso que aconteceu com a Psicologia. Foi muito prático, muito aplicável. (E1)
\end{abstract}

As entrevistas apontaram a possibilidade de o aluno que não se sinta preparado emocionalmente abandonar o curso ao se deparar com situações da rotina da Enfermagem, com atividades que deverá realizar futuramente em sua vida profissional. Neste contexto, a imaturidade é destacada como possível determinante da desistência do curso:

Eu...no segundo dia que eu fui pro estágio, eu pensei em desistir. Pensei X?! Quando eu entrei, eu estava as..., primeiro dia nós só observamos, que foram assim, os pacientes que estavam lá todos eles eram... já estavam em fase terminal, um HIV e outro com câncer. Aí nós fomos fazer os procedimentos e tal. Eu não, não estava preparada, eu.. eu falei: "gente! eu acho que eu vou desistir! Não é isso que eu quero para minha vida, não!" (E7)

\section{Expectativas frente à disciplina cursada e limitações constatadas}

Como limitações da disciplina Psicologia Aplicada à Enfermagem os alunos apontaram a necessidade de ampliar a carga horária para que pudessem tomar conhecimento de outros conteúdos de Psicologia não apresentados e, ainda, compreender totalmente os que foram discutidos em sala. Também foi apontada a relação entre esta disciplina e os conteúdos ministrados em Ética Profissional:

São três aulas de Psicologia, três sábados, então foi muito corrido, foi muito dinâmico, mas o que faltou foi ela [professora] falar mais, assim, da postura. Eu sei que isso é mais da ética, mas a maioria do pessoal usa a ética e a ética vem junto com a psicologia. (E8)
Outra limitação apontada referiu-se à necessidade de um espaço, na própria disciplina, destinado a preparar emocionalmente os alunos, antes de entrarem no estágio, para lidar com algumas situações e temas que surgem na área de Enfermagem como, por exemplo, a morte, a dor e o abandono a que são submetidos muitos pacientes, no sentido de eles poderem oferecer a esses pcientes o apoio adequado. Um entrevistado sugere que a professora

\begin{abstract}
no decorrer agora , ... dessas novas turmas que forem entrando, ela poderia pensar nesta proposta...de trabalhar, também o aluno, né, antes, de, de ir pro hospital, porque eu acho que tem muita coisa, assim, que choca... (E7)
\end{abstract}

No que se refere às expectativas relacionadas à disciplina, os estudantes imaginavam que ela abarcasse orientações sobre como atender o paciente e como proceder diante de algumas situações que ocorrem no hospital, no dia a dia da profissão.

Não, eu pensei que fosse assim: uma forma de orientar o técnico de enfermagem, como ele poderia proceder dentro do hospital, né? Diante de algumas situações que ele se deparasse na frente. Na... na... na minha imaginação era isso. (E7)

Outros alunos imaginaram que estudariam autores clássicos, como Freud, de modo que não haveria relação entre o tema estudado e a aplicação desse conteúdo na prática profissional.

Quando eu ouvi falar que a gente ia ter psicologia na grade, eu achei que fosse ser muito chato, que a gente fosse ver a vida de Freud, enfim, de, de grandes psicólogos ... esse foi, essa foi uma, a minha visão. Mas depois que eu vi que tem coisas tão práticas, que a gente ... é.. é... Psicologia é a gente, né? ...tirei essa visão de... de que é uma coisa chata, entendeu? (E1)

Em se tratando do contato com a referida matéria, os alunos que já tinham estudado Psicologia em outro curso apresentaram certa familiaridade com os assuntos debatidos em sala e facilidade em relação a eles, visto que alguns eram comuns nos dois cursos:

Eu já tive [Psicologia], tive no curso de formação de professores. Falava sobre ego, superego, inconsciente ...toda essa parte aí eu já tive ...as pesquisas do...acho que ...Pavlov, né? tinha outro também....Freud, 
eu estudei sobre essas escolas. Então eu já tive uma ideia bem clara. Então quando a professora passou sobre essa matéria, eu não tive a dificuldade, porque eu já tive já, vim de anos passados. (E4)

Já os alunos que não tiveram contato anterior com a disciplina mencionaram a imagem popular associada à Psicologia indicada para tratar "loucos", como relata o primeiro entrevistado: "Assim, a gente é, ouve muito que, quem precisa de Psicólogo é louco, né?”

Curiosamente, quatro dos dez entrevistados já tinham sido atendidos por profissional de psicologia/psicoterapia. Essa informação, embora não fizesse parte do roteiro, foi obtida espontaneamente ao longo da entrevista:

Olha, a Psicologia, então não tinha ...eu já tinha uma certa...um certo conhecimento da Psicologia, porque quando era menor eu já tinha, eu fazia acompanhamento porque eu tive psoríase. Que eu tinha não, tenho, por causa de problemas de fundo emocional, né? Então meus pais me levaram pra psicólogo. (E8)

\section{DISCUSSÃO}

De acordo com os entrevistados, a Psicologia pode ajudar o profissional de enfermagem na compreensão do comportamento do paciente, bem como a vê-lo de forma integral; mas no que tange às expectativas quanto à disciplina Psicologia Aplicada à Enfermagem, os alunos entrevistados expressam a necessidade de um "roteiro de condutas" a ser seguido pelo profissional. Tal anseio por condutas predefinidas difere da concepção de Manzolli (1985) de que o ensino da Psicologia não deva ser fixado em fórmulas e em conteúdos de bom desempenho do enfermeiro.

Kobayashi e Leite (2004), com base no Parecer n. ${ }^{o}$ 16/99 do Conselho Nacional de Educação (CNE) e da Câmara de Educação Brasileira (CEB), afirmam que não se desenvolve competência sem as capacidades de "julgar, considerar, discernir e prever os resultados de distintas alternativas, eleger e tomar decisões" (Kobayashi \& Leite, 2004, p.224). A competência profissional é construída a partir da

articulação e mobilização de valores, conhecimentos e habilidades para resolução de problemas não só rotineiros, mas também inusitados em seu campo de atuação profissional, superando a experiência acumulada já transformada em hábito e liberando o profissional para a criatividade e atuação transformadora (Kobayashi \& Leite, 2004, p.224).

Se por um lado existe a possibilidade de serem necessárias receitas prontas, por tratar-se de profissionais ainda em formação, por outro podemos atribuir este desejo à falta de articulação entre os conteúdos estudados e as situações encontradas no hospital. Os conteúdos discutidos ao longo da disciplina "Psicologia Aplicada à Enfermagem" apresentam-se muito mais próximos de áreas mais tradicionais ou antigas de investigação psicológica (como a Psicologia da Personalidade, por exemplo) do que de áreas mais recentes, com as quais o diálogo entre Psicologia e Enfermagem também pode florescer. São exemplos a Psicologia Hospitalar e da Saúde (Castro \& Bornholdt, 2004).

A necessidade, apontada pelos entrevistados, de desenvolver algumas características, como a paciência e controle emocional, para conseguirem desenvolver de forma satisfatória suas atividades ao longo do estágio vai ao encontro de estudo desenvolvido por Filizola e Ferreira (1997) que trata do envolvimento emocional da equipe de enfermagem com o paciente. Os autores discutem a necessidade de o profissional aprender a controlar sentimentos e a refrear envolvimento excessivo com o paciente, e assinalam que envolver-se implica em perceber o outro como pessoa, não como objeto. Perceber o outro enquanto pessoa "atrapalharia" o trabalho da enfermagem, na medida em que, ao dedicar-se a um paciente, o profissional "esqueceria" outros. Do mesmo modo, segundo Filizola e Ferreira, esse profissional deixaria de executar tarefas necessárias ao cuidado, por sentir "pena" do paciente. É desprezada, neste caso, a individualidade, a singularidade do paciente, que poderia aflorar durante um contato mais próximo. Concordamos com os autores, que destacam a necessidade de o aluno "controlar" seus sentimentos, de modo a prevalecer o domínio técnico no exercício da enfermagem, o que tem a desvantagem de dificultar uma visão mais integral do paciente. Por outro lado, também concordamos com Casate e Corrêa (2006) ao apontarem que o estágio permite que, ao vivenciar situações conflitivas e complexas, o aluno se depare com o sofrimento do paciente e, a partir disso, perceba-se vulnerável e frágil, ao mesmo tempo em que se torna sensibilizado para o exercício do cuidado, utilizando como ferramentas seu senso crítico e o acolhimento. A fala dos alunos entrevistados em nossa pesquisa sobre a necessidade de "controlar" sentimentos nos coloca diante da dicotomia do fazer técnico e do fazer humano, como ressaltam Casate e Corrêa (2006). Tal dicotomia é vista pelos autores 
como uma limitação para a humanização das ações em saúde, e requer o acolhimento do aluno estagiário, com a possibilidade de discussão/reflexão sobre as limitações e conflitos apresentados por esse aluno, ressaltando-se não apenas o domínio técnico obviamente necessário à sua atuação - mas também seus aspectos humanos.

Por outro lado, ao se referirem às limitações da disciplina, os estudantes apontam a necessidade de um espaço de preparação emocional antes de ingressarem no estágio profissionalizante, capaz de acolher dúvidas e anseios referentes ao início da prática, bem como dificuldades que poderiam surgir durante as atividades. Considerando o momento delicado que o aluno se encontra, de contato recente com uma prática que ele desconhece e que lhe causa impacto, podemos pensar em algumas ações das instituições de ensino e assistência. Conforme referido em estudo de Backes, Koerich e Ferdmann (2007), o processo de humanização, ao compreender também a lógica do estudante e trabalhador, sinalizaria para o trabalho enquanto instrumento humanizador e/ou desumanizador .

A "conversa" identificada na fala dos entrevistados como importante no contato com o paciente é entendida como o meio pelo qual o técnico aborda as questões psicológicas do doente e a forma como a disciplina de Psicologia mostra-se presente em sua prática. De acordo com a Política Nacional de Humanização (Brasil, 2006), podemos substituir o termo "conversa" por "escuta".

$\mathrm{Na}$ importância atribuída à "conversa", à proximidade do paciente e ao apoio, observamos a concepção dos estudantes sobre a existência de interação entre aspectos psíquicos, sociais e físicos, pois do contrário a presença e disponibilidade do profissional em dialogar e ouvir o paciente não acarretaria as mudanças positivas apontadas nas entrevistas. De acordo com a cartilha sobre "Acolhimento nas Práticas de Produção de Saúde" (Brasil, 2006), a palavra acolher pode ser compreendida como "estar com" ou "estar perto" de alguém, portanto é importante ferramenta para romper com processos de "anestesia" de nossa escuta e de produção de indiferença diante das necessidades e diferenças apresentadas pelo outro. Tal indiferença teria por função assegurar-nos uma enganosa sensação de proteção contra o sofrimento apresentado pelo outro, mas terminaria por isolar e entorpecer o ser humano, tornando-o insensível à dor alheia.

Com relação à escuta, os entrevistados apontaram que às vezes o paciente necessita de uma atitude mais diretiva, funcionando como um auxílio moral, um apoio, ou de uma troca de ideias, levando a um alívio imediato com efeito catártico, ou clarificando os conflitos (Campos, 1995). Assim como ouvir e conversar com o paciente, para os entrevistados, o profissional precisa também incorporar "delicadezas", "gentilezas" [sic] ao relacionar-se com ele. Isso vai ao encontro das Diretrizes Curriculares Nacionais, segundo as quais a nova visão de saúde inclui a humanização do cuidado na perspectiva do cliente "envolvendo um conjunto de 'amenidades' de trato e de possibilidades de escolhas onde se incluem os aspectos éticos" (Diretrizes Curriculares Nacionais para o Ensino Técnico Área da Saúde, 1999, p.4).

O cuidado, definido como ato humanitário, é o modo pelo qual, segundo os entrevistados, torna-se possível atender a todas as necessidades do indivíduo, devendo ser realizado de forma afetuosa, como se fosse a um familiar. $O$ cuidado prestado pela enfermagem, segundo os alunos, ultrapassa a enfermidade, o funcionamento físico do doente.

As entrevistas aqui apresentadas corroboram uma pesquisa (Lima, Oliveira, Cade, Rabello \& Santana, 2005) a respeito das ações do cuidar da equipe de enfermagem. Fundamentadas no saber, no fazer e no sentir, tais ações encontram-se voltadas ao atendimento das necessidades do paciente em suas diversas fases da vida, comprometidas com a proteção, promoção e preservação da vida. A orientação para o cuidar em enfermagem deverá ser holística (termo cuja origem, "holos", quer dizer "todo"), pois além de atender à cura, quando possível, atenderá a pessoa na sua globalidade, considerando as dimensões biológica, psicológica, social, cultural e espiritual daquele que se torna-se objeto de seu cuidado com vista a seu bemestar (Ribeiro, 2002). A necessidade de ouvir/conversar com o paciente, identificada a partir das falas dos alunos entrevistados, aponta para essa visão ampliada daquele que é alvo de cuidados.

Não obstante, o grande desafio para a enfermagem não é só transformar o paradigma atual de um modelo tecnicista de cuidado, de cunho curativo, centrado na alta tecnologia (Lima, Oliveira, Cade, Rabello \& Santana, 2005) e na intervenção do agravo já estabelecido, mas sim, formar profissionais que compreendam o cuidado de enfermagem como direito de cidadania, fundamentado num profundo respeito ao lidar com as pessoas. A legislação que regulamenta o ensino profissionalizante de Enfermagem apresenta a tendência de formar profissionais, ou seja, pessoas com competências que lhes permitam transcender à fragmentação de tarefas existente (Kobayashi \& Leite, 2004). 
A concepção humanitária do cuidado em enfermagem esteve sempre presente no imaginário sociocultural, a partir do cuidado prestado pelas mães ou pelas instituições caritativo-religiosas, embora ocorra a crescente conciliação com o pensamento técnico-científico impulsionado pelo paradigma holístico nas ciências (Vieira, 1999); mas o que se observa nas entrevistas é que, apesar da consideração aos princípios da integralidade e do aparente esforço para se chegar a uma relação satisfatória entre profissional e cliente, dentro de determinados limites, parece haver uma leve tendência a aproximar a Enfermagem à prática da caridade, que pode ser visualizada em argumentos e expressões utilizados pelos estudantes para se referir ao "cuidar".

Assim, partindo-se da perspectiva que a tarefa primordial da Enfermagem é a assistência a outras pessoas - para a qual se utilizariam o pensamento, as atitudes e os sentimentos no relacionamento, de modo a superar a forma impensada, casual e impessoal de lidar com o ser humano -, e levando-se em consideração que esta é a principal motivação da maioria dos alunos que procuram o curso de enfermagem (Ribeiro, 2002), pode-se questionar se a formação profissional vai ao encontro desta predisposição do aluno e se esta relação de ajuda estabelecida entre profissional epaciente tem sido realizada de forma equilibrada.

\section{CONSIDERAÇÕES FINAIS}

Como afirmado anteriormente, a disciplina de "Psicologia Aplicada á Enfermagem" constitui importante ferramenta para o entendimento $e$ realização satisfatória da relação de ajuda presente na assistência em Enfermagem. Por outro lado, enquanto área do conhecimento científico e inserção profissional, a Psicologia oferece, de forma mais ampla, contribuições científicas, clínicas e educativas para a prática de saúde de forma geral. Estando presente na formação técnica profissional de Enfermagem, a disciplina de Psicologia, da mesma forma que ocorre com a atuação do psicólogo em instituições hospitalares, tem como foco a subjetividade do ser humano que adoece; mas para tanto os conteúdos discutidos com os alunos na disciplina "Psicologia Aplicada à Enfermagem" necessitam de ampla revisão. Neste sentido, vale destacar a necessidade de um conteúdo crítico, capaz de levar o estudante a discutir e perceber sua aplicabilidade no exercício de sua profissão, superando um conhecimento geral, impessoal, desvinculado da rotina de trabalho. Esta visão nos reporta ao lema principal dos movimentos pela humanização da saúde, o qual também tem sido alvo da formação técnica profissional e da Psicologia no contexto hospitalar: a consideração e respeito às singularidades de cada ser humano -paciente ou profissional - envolvido no processo saúde-doença.

Embora aceita como um princípio que integra a formação técnico-profissional, a humanização tem sido mais claramente observada a partir da atuação e iniciativas do psicólogo que atua em instituições de saúde. Como justificativa para esta situação podemos referir a disponibilização desse profissional em viabilizar de forma concreta a interlocução entre as diversas categorias de trabalhadores no locus onde surgem suas principais dificuldades. A participação do psicólogo numa equipe interdisciplinar não busca uma síntese de saberes, tão pouco procura se sobrepor aos demais profissionais, mas viabilizar a substituição da hegemonia do saber médico pela interlocução entre os diversos profissionais, que se unem aos profissionais de medicina para o bem-estar integral do ser humano. Talvez aqui esteja o ponto de partida para começarmos a pensar na mudança pretendida para os currículos de educação técnico-profissional na área de Enfermagem -consequentemente, para o cenário da assistência prestada por estes profissionais. Tal mudança deve envolver o reconhecimento de todas as disciplinas como vitais para o "cuidar" em saúde, e ainda a participação da Psicologia, para viabilizar a reflexão sobre temas atuais - como bioética, políticas sanitárias e morte - que há muito integram a formação dos psicólogos que se especializam para a atuação em instituições hospitalares, o que tanto contribui para uma visão diferenciada sobre saúde.

\section{REFERÊNCIAS}

Avello, I. M. \& Grau, C. F. (2004). Enfermagem. Fundamentos do Processo de Cuidar. São Paulo, DCL.

Backes, D. S., Koerich, M. S. \& Erdmann, A. L. (2007). Humanizando o cuidado pela valorização do ser humano: resignificação de valores e princípios pelos profissionais de saúde. Revista Latino-Americana de Enfermagem, 15(1) Recuperado em 8 de dezembro de 2008 de http://www.scielo.br

Bagnato, M. H. S., Bassinello, G. A. H., Lacaz, C. P. C. \& Missio, L. (2007). Ensino médio e educação profissionalizante em enfermagem: algumas reflexões. Revista da Escola de Enfermagem da USP, 41(2). Recuperado em 8 de dezembro e 2008 de http://www.scielo.br

Biasoli-Alves, Z. M. M. \& Dias da Silva, M. H. G. F. (1992). Análise qualitativa de dados de entrevista: Uma proposta. Paideia Cadernos de Educação, 2, 61-69.

Brasil. Ministério da Saúde (2006). Acolhimento nas práticas de produção de saúde. Brasília, Ministério da Saúde, 44 (Série B. 
Textos Básicos de Saúde) Recuperado em 03 de janeiro de 2010 em portal.saude.gov.br

Campos, T. C. (1995). Psicologia Hospitalar. A atuação do psicólogo em hospitais. São Paulo, E.P.U.

Casate, J. C. \& Adriana Katia Corrêa, A. K. (2006). Vivências de alunos de enfermagem em estágio hospitalar: subsídios para refletir sobre a humanização em saúde. Revista da Escola de Enfermagem USP, 40(3), 321-328. Recuperado em 03 de janeiro de 2010 em www.ee.usp.br/reeusp

Castro, E. K. \& Bornhold, T. E. (2004). Psicologia da saúde x psicologia hospitalar: definições e possibilidades de inserção profissional. Psicologia Ciência Profissão, 24(3), 48-57.

Conselho Regional de Enfermagem do Rio de Janeiro. (2008). Estatística de Inscritos. Recuperado em 8 de dezembro de 2008 em http://www.coren-rj.org.br

Dantas, R. A. \& Aguillar, O. M. (1999). O ensino médio e o exercício profissional no contexto da enfermagem brasileira. Revista Latino-americana de Enfermagem, 7(2) Recuperado em 8 de dezembro de 2008 em http://www.scielo.br

Diretrizes Curriculares Nacionais para o Ensino Técnico Área da Saúde. (1999, 27 de abril). Brasília, Ministério da Educação, Ministério da Saúde. Recuperado em 8 de dezembro de 2008 em http://www.opas.org.br/rh/admin/documentos/diretrizes_curricula res.pdf

Filizola, C. L. A. \& Ferreira, N. M. L. (1997). O envolvimento emocional para a equipe de enfermagem: realidade ou mito? Revista Latino-americana de Enfermagem, 5 Recuperado em 8 de dezembro de 2008 em http://www.scielo.br
Fontinelle Junior, K. (2002). Ética e Bioética em Enfermagem. Goiânia: AB.

Kobayashi, R. M. \& Leite, M. M. J. (2004). Formação de competências administrativas do técnico de enfermagem. Rev. Latino-americana de Enfermagem, 12(2), 221-227.

Lima, R. C. D., Oliveira, E. R. A., Cade, N. V., Rabello, M. L. \& Santana, L. G. (2005). O Processo de Cuidar na Enfermagem: Mudanças e Tendências no Mundo do Trabalho. Cogitare Enfermagem, 10(2), 63-67.

Manzolli, M. C. (1985). Formação do Enfermeiro. Contribuições da Psicologia. São Paulo, Sarvier.

Ribeiro, G. (2002). O Cuidar. Análise Reflexiva de um conceito. Monografia de Graduação Não-Publicada, Graduação em Enfermagem, Escola Superior de Enfermagem Maria Fernanda Resende, Lisboa. Recuperado em 7 de maio de 2008 em http://www.geocities.com/soneca_mfr/Cuidar.doc

Vieira, M. J. A. (1999). Representação do cuidar na imagem cultural da enfermagem. Revista Latino-Americana de Enfermagem, 7(5) Recuperado em 8 de dezembro de 2008 em http://www.scielo.br

Recebido em 19/01/2009 Aceito em 19/03/2010
Endereço para correspondência:

Renata Fabiana Pegoraro. Rua 227 Qd 67A Lt 3/4 Setor Leste Universitário, CEP 74605-080, Goiania-GO, Brasil.E-mail: rfpegoraro@yahoo.com.br. 